\title{
ENTRE A INOVAÇÃO E O PLANEAMENTO. NOVOS MODELOS DE GESTÃO DAS COMPRAS HOSPITALARES
}

\author{
Alexandre Dinis Poeta \\ Fernanda Nogueira \\ José Maria Andrade*
}

\begin{abstract}
Quando se analisam novas propostas de dinâmicas para a gestão pública, uma das principais constatações é que a normatividade das mesmas constitui como que um labirinto, para o qual dificilmente se encontrará uma saída no campo da inovação. No entanto, face à rápida mudança da sociedade, da tecnologia e da economia actuais, as Instituições Públicas terão de dar os primeiros passos, abandonando, de alguma forma, a gestão beneficente, paternalista e burocrática que têm vindo a desenvolver, em busca de uma outra planeada em função da procura e da inovação.

Este artigo reflecte algumas destas preocupações, enunciando os princípios teóricos fundamentais a considerar na criação de uma Central de Compras para as Unidades Hospitalares e Sub-Regiões de Saúde da Zona de Intervenção da Administração Regional de Saúde do Norte, sem descurar os interesses dos principais destinatários (doentes, equipes técnicas, etc.). Mais especificamente, os autores apontam algumas das implicações administrativas e de gestão decorrentes da reestruturação da cadeia de valor explícita na centralização da aquisições.
\end{abstract}

Palavras-Chave: Cadeia de valor, gestão logística, central de compras: estrutura interna e externa.

\footnotetext{
* Docentes do Departamento de Economia e Sociologia da Universidade de Trás-osMontes e Alto Douro (UTAD).
} 


\section{INTRODUÇÃO}

No século XIV o mundo vivia uma fase de grandes mudanças, enquanto a sociedade feudal se apresentava de forma completamente desestruturada, a burguesia procurava novas formas para comercializar os seus produtos. Surge, então, e pela primeira vez, um conceito que começa a transformar as relações económicas; a ideia de lucro. Passados mais de cinco séculos, este pensamento domina a civilização ocidental, ao ponto de nos perguntarmos como pôde ter havido uma época em que a ideia de lucro não existia.

Actualmente, não equacionamos apenas as receitas e as despesas, é necessário que as despesas sejam menores que as receitas por forma a que o excedente nos permita fazer face a situações imprevisíveis de reinvestimento, expansão ou inovação das actividades ou práticas de gestão. O acompanhamento desta caminhada, por parte da Administração Pública, tem--se revelado difícil, dada a sua permanente dificuldade de integração entre políticas e novas técnicas de gestão, tantas vezes antagónicas durante a sua actuação.

É neste contexto que as Instituições Públicas, com toda a sua complexidade de actuação, terão de dar os primeiros passos, procedendo, para tal, ao abandono de uma gestão puramente beneficente, paternalista e burocrática, em busca de uma outra estruturada em função da procura. Mas, falar em gestão da Coisa Pública pressupõe ter-se presente todo um conjunto de necessidades individuais e colectivas cuja satisfação é assumida como tarefa fundamental por toda a comunidade. No entanto, tal tarefa, apesar do seu carácter perene e indiscutível, não implica a sua satisfação de qualquer forma e a qualquer preço. Tentando adaptar alguns conceitos advindos do campo da gestão empresarial à gestão da Coisa Pública podemos dizer que, não basta procurar a eficiência, é necessário alcançar a eficácia, associando- -se-lhe indeclinavelmente, uma qualidade acrescida, através da implementação de processos de gestão inovadores, os quais devem permitir que se processe, nas Instituições públicas, uma gestão que funcione; funcione melhor e gaste menos; se reveja no modo como deveria funcionar e não no que deveria fazer.

Tendo presente toda esta problemática, é objectivo central do presente estudo a concepção de uma unidade de centralização, para aquisição de bens e serviços, com destino às unidades de consumo da zona de intervenção da Administração Regional de Saúde do Norte (ARS-Norte). 


\section{ENQUADRAMENTO E SITUAÇÃO ACTUAL}

\subsection{Modelos de Gestão Pública: um debate oculto}

Quando se analisam propostas de novas dinâmicas, para a gestão pública (Universidades, Hospitais, Associações Profissionais e Comerciais, etc.), uma das principais constatações é a de que a normatividade das mesmas constitui como que um labirinto, para o qual dificilmente se encontrará uma saída no campo da inovação. No entanto, qualquer uma destas instituições sentirá esta necessidade, de inovação, face à rápida mudança da sociedade, da tecnologia e da economia actuais.

Com esta preocupação presente, vários têm sido os autores que, de alguma forma, têm contribuído para a definição de modelos de gestão da Coisa Pública. Em 1995, Holmes e Shand apresentam uma caracterização genérica dos modelos de gestão pública, salientando os seguintes atributos: a) carácter estratégico ou orientado para os resultados do processo decisório; b) descentralização; c) flexibilidade; d) desempenho consciente; e) competitividade interna e externa; f) definição de estratégias; g) transparência e responsabilidade pelos resultados; etc.

Ainda sobre os atributos dos modelos de gestão pública, Rocha referia em 1996 que para se conseguir um modelo de "boa" gestão é necessário que o mesmo contenha: a) racionalidade; b) flexibilidade; c) leveza; d) adesão e comprometimento dos agentes; e) neutralidade; f) igualdade de tratamento; g) probidade dos agentes.

Se, por um lado, estas caracterizações são suficientemente genéricas para abarcar os diferentes vértices dos modelos de gestão pública, por outro, tornam-se de pouca ou nenhuma utilidade para revelar a imagem e o projecto do estado, subjacente a estes modelos. Queremos com isto dizer que, qualquer que seja o modelo a aplicar à gestão pública, este terá de enfrentar os poderosos obstáculos que são a cultura instalada e os procedimentos burocráticos. De outra forma, perspectivar e viver a gestão pública começa, sem dúvida, por desafiar a sua cultura tradicional, facto que, como é o caso português, se confronta com a barreira dos "códigos napoleónicos", em que domina a perspectiva da responsabilização e do acatamento pelas rotinas, estilo oposto ao do empenho e da responsabilidade pela obtenção de resultados pré-determinados.

Tentando ir um pouco mais longe e compartilhando a opinião de Camacho et al., já em 1982, a gestão pública no seu conjunto, e em particular as relações de fins e meios, caracteriza-se pela desarticulação entre os dois sistemas coexistentes, não se obtendo uma resposta satisfatória de qualquer deles no que respeita às seguintes questões: 
a) coerência entre fins e meios; causalidade (nexo de), complementaridade e sinergia.

b) rentabilidade dos meios (utilidade social); custos das acções, aplicações alternativas.

c) responsabilização pela aplicação dos meios: finalização das aç̧ões (para que servem), mecanismos de controle.

Ainda segundo o mesmo autor uma articulação lógica, entre os fins últimos (do público alvo) e os meios (elementos a mobilizar pela gestão pública para seu alcance), consistiria em inserir entre os meios (entradas, inputs) e os fins (saídas, outputs), actividades organizadas sob a forma de acções finalizadas, com as seguintes dimensões: quando (tempo), como (estrutura das actividades) e quem (estrutura dos serviços). Tal esquema pressupõe, no entanto, a existência concomitante de mecanismos institucionais adequados à integração coerente dos três vectores a contemplar, assentes numa vontade política forte; duma filosofia orientada e dum corpo de técnicas que sirvam de suporte ao processo preconizado.

As mudanças verificadas nos serviços públicos, nomeadamente nos serviços de saúde, quer através da externalização de alguns, quer através da partilha de outros pelo sector público e privado, requerem por parte das instituições públicas a adopção de uma nova filosofia de gestão.

Quadro I

COMPARAÇÃO ENTRE MODELOS

\begin{tabular}{|l|lr|}
\hline \multicolumn{1}{|c|}{ ANTIGO MODELO } & \multicolumn{1}{|c|}{ NOVO MODELO } \\
\hline $\begin{array}{l}\text { Responsabilização e acatamento pelas } \\
\text { rotinas }\end{array}$ & $\begin{array}{l}\text { Empenho e responsabilidade pela } \\
\text { obtenção de resultados }\end{array}$ \\
\hline Normatividade e burocracia & Inovação e flexibilidade \\
\hline $\begin{array}{l}\text { Sistema fechado, sem a participação de } \\
\text { muitos dos interessados }\end{array}$ & $\begin{array}{l}\text { Estratégia, competitividade } \\
\text { participação }\end{array}$ \\
\hline Desarticulação entre os fins e os meios & Coerência e rentabilização dos meios \\
\hline
\end{tabular}

\subsection{O processo logístico: alguns estrangulamentos}

Um dos objectivos prioritários da ARS-Norte, tentando dar corpo técnico a uma nova filosofia de gestão hospitalar no âmbito da gestão dos recursos disponíveis, é a racionalização e optimização dos processos de aprovisionamento de produtos e serviços para todas as Unidades de Consumo Hospitalar e Sub-Regiões de Saúde da sua Zona de Intervenção. 
O importante volume de recursos financeiros, destinados à aquisição de materiais e contratação de serviços, conjuntamente com a grande multiplicidade dos mesmos e a pluralidade das Unidades de Consumo com autonomia própria, leva a que se equacione apossibilidade de uma gestão logística integral das referidas unidades de consumo, com vista à melhoria dos processos de aprovisionamento e à obtenção de resultados que conduzam a um incremento de eficiência, na utilização dos recursos.

Assim, e mediante uma primeira análise, podemos começar por referir que, actualmente, o sistema de compras hospitalares se caracteriza pela adjudicação mediante concurso público individual, por parte de cada uma das Unidades de Consumo. Este sistema apresenta, entre outros, os seguintes entraves ao nível do processo logístico na cadeia de valor (fig. 1):

Figura 1

\section{PROCESSO LOGÍSTICO}

Fornecedores

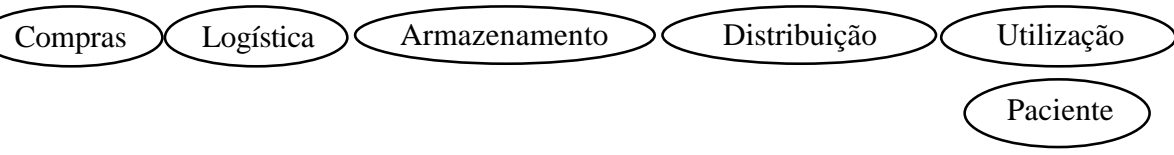

??Ao nível das compras; o número elevado de referências, os muitos fornecedores por referência sem critérios de selecção, os elevados gastos de tempo por parte da função compra na formulação e emissão de pedidos, a falta de informação sobre o mercado e os fornecedores e o insuficiente suporte informático para manipular o volume de dados necessários.

??Ao nível da logística: as deficiências nas entregas (erros de destinatários, erros quanto às referências, não cumprimento dos prazos de entrega), a não optimização da frequência das entregas e a falta de controlo das entregas já vencidas.

??Ao nível do armazenamento: os múltiplos armazéns, os devados níveis de "stocks", as rupturas de "stocks", a manutenção em armazém de produtos fora de prazo, a não utilização do potencial da tecnologia informática (código de barras) e o desenho inadequado dos armazéns, o que dificulta as entregas e o controlo dos "stocks".

??Ao nível da distribuição interna: a lenta e pouco frequente distribuição interna e o número elevado de pedidos urgentes.

?'Ao nível da utilização: são os médicos quem tomam grande parte das decisões, o que implica uma atomização de critérios, uma grande 
variedade no uso de produtos e a pouca estandardização dos mesmos, não se dispondo, em muitos casos, de informação detalhada (consumo, custo total, etc.) e não existindo mecanismos formalizados no sentido de aproveitar a inovação.

\subsection{Análise da "Cadeia de Valor"}

Podemos definir o conceito de cadeia de valor da seguinte forma: "conjunto de actividades de criação de valor desde as fontes de matérias-primas até ao produto acabado ou serviço que se entrega aos clientes". É um desenvolvimento do antigo conceito contabilístico de valor acrescentado, como sendo a diferença entre o valor das compras e o das vendas. Essa diferença deve ser o mais acentuada possível através da pressão que se possa exercer, tanto sobre os fornecedores como sobre os clientes. Com esta nova perspectiva o cliente e o fornecedor assumem um novo posicionamento na cadeia de valor.

Quando uma empresa ocupa um posicionamento subóptimo numa determinada cadeia de valor, o seu principal desafio estratégico é reposicionar-se nos elos com maiores potencialidades de gerar valor acrescentado. Daí que dois grandes reposicionamentos se possam equacionar: mudança de um elo para o outro e ocupação de maior número de elos do que antes, quer a montante quer a jusante. Claro que, neste caso, trata-se de uma cadeia de valor que, extravasando o limiar entre o público e o privado, o seu reposicionamento estratégico é mais em prol da eficiência do que do incremento do valor acrescentado no sentido mais monetário do termo.

Tipicamente, o hospital público, em termos das suas transações a montante, compra três tipos de produtos: material de consumo clínico; produtos farmacêuticos e equipamentos. Cada uma destas categorias tem uma cadeia de valor diferente e uma estrutura de intermediação diferenciada.

Importa salientar que na actual cadeia de valor, o médico não é um mero interveniente técnico, mas desempenha uma função fundamental de intermediação entre os fornecedores e unidades de consumo (hospitais e sub-regiões de saúde), sobretudo na especificação de determinados produtos. Significa isto que o médico se situa entre a unidade de consumo e as várias fileiras de fornecedores. A criação da central de compras, bem como a implementação de novos modelos de gestão, implica uma partilha concertada de todos os intervenientes no processo de decisão.

Para além disso, a gestão dos produtos deve ser enquadrada num sistema de decisões descentralizado, de modo a aproximar os critérios de decisão dos consumidores e dos clientes. Por outro lado, concentrar os poderes de 178 
negociação, na central de compras, fortalece o posicionamento das unidades de consumo na cadeia de valor e melhora a eficiência do aprovisionamento. Dito de outra forma, equacionar as possibilidades de uma associação estratégica (criação da Central de Compras) pode favorecer o posicionamento das Instituições de saúde, convertendo as potenciais sinergias em activos.

Quando nos encontramos imersos num mercado competitivo, em certa medida fragmentado e (ou) de evolução muito rápida, deve procurar ser-se flexível, inovador e possuir capacidade de adaptação à realidade em constante mudança. E isso apenas parece possível, principalmente nas grandes organizações, descentralizando a tomada de decisões e desenvolvendo processos e métodos que permitam um reposicionamento mais eficiente quer dos fornecedores quer dos clientes na cadeia de valor. Esta é a realidade do sector dos serviços.

Nas grandes unidades de saúde existem muitas sinergias entre as actividades, pelo que a descentralização deve integrar mecanismos para que estas sejam respeitadas. Determinados aspectos da política de compras constituiriam alguns desses mecanismos. Admitir que se pode descentralizar as responsabilidades, mas não as decisões sobre os aprovisionamentos, põe em causa a coerência interna do desenho funcional da organização.

Uma vez mais se deve dar especial atenção aos sistemas de informação e aos canais de comunicação interna. Se não são adequados, não é possível descentralizar, nem tão pouco implementar sistemas eficientes de aprovisionamentos.

\section{BASES PARA UM MODELO DE CENTRAL}

Os contactos diários com responsáveis de instituições, dos mais diversos sectores da actividade económica, permitem constatar que se lhes apresenta, neste momento, uma situação exigente, pedindo-lhes o máximo das suas capacidades e esforço para enfrentar um conjunto de problemas, ao nível da gestão de aprovisionamentos, verdadeiramente difíceis. Para enfrentar tal conjunto de problemas, como deverá proceder o Gestor dinâmico e empreendedor que desejamos ver à frente das nossas Instituições?

Pensamos que perante tal situação esses responsáveis devem, tão rapidamente quanto possível, estabelecer ou reformular os métodos de gestão, bem como equacionar, cuidadosamente, os meios de que dispõem no sentido da sua eficiente utilização. Com efeito, torna-se imperioso encontrar resposta pronta a perguntas como:

1. Dispõe a instituição de objectivos e planos para atingir as metas a longo prazo? 
2. Os gestores, responsáveis pelos diversos sectores de actividade, sabem com clareza o que fazer para implementar esses planos?

3. Estão identificadas as áreas de actuação onde importa melhorar os resultados?

4. A equipa de gestores dispõe de instrumentos para atingir as metas que satisfaçam os objectivos da instituição?

5. Chegou-se a acordo sobre os padrões da actuação a manter? Faz-se uma revisão sistemática dos resultados atingidos e do potencial dos recursos humanos?

A resposta a perguntas deste tipo, implícitas quer nas fases iniciais de elaboração dos planos, quer nas fases de restruturação organizacional da instituição, não é, em geral, fácil e obriga a uma disciplina e metodologia de pensamento extremamente rigorosas. Com esta nova abordagem abandonase o velho conceito administrativo, mais preocupado com os aspectos burocráticos, desenhando-se um modelo dinâmico e participativo, orientado para a optimização da função logística do aprovisionamento, como subsidiária da função assistencial.

O modelo de gestão, que se apresenta, foi concebido tendo por base o marco conceptual da gestão participativa por objectivos ${ }^{1}$ e assente em instrumentos de gestão contratual como o outsourcing, a centralização da negociação/aquisição/distribuição, ou as Plataformas de Compras, para citar alguns deles. Sem dúvida que estas ferramentas são de muita utilidade e transportam consigo grande valor acrescentado, mas não deixam de ser instrumentos de gestão integrados num modelo de gestão logística orientado para a optimização das distintas variáveis que o integram, com o objectivo de facilitar o desenvolvimento da função principal: o Serviço de Assistência.

\subsection{Objectivos estratégicos}

As grandes linhas de actuação, que determinam a gestão logística, orientam-se no sentido de alcançar os seguintes objectivos estratégicos:

1. Garantir a disponibilidade de produtos para o correcto funcionamento da actividade assistencial;

2. Optimizar a relação qualidade/preço/serviço/prazos;

3. Adequar a estrutura organizacional e a legislação aos novos modelos de gestão.

A primeira linha estratégica mencionada corresponde à própria natureza do serviço de aprovisionamento: garantir a disponibilidade de produtos para o correcto funcionamento da actividade assistencial. Isto pressupõe a necessidade de definir um catálogo de produtos e determinar, dentro desse catálogo, as especificidades de cada serviço ou centro de custos, assim 180 
como dimensionar adequadamente os "stocks", articular acções complementares e substitutas capazes de dar resposta em quantidade, tempo e forma às necessidades assistenciais. A experiência demonstra que o factor que mais penaliza e deslegitima o sistema logístico é a falta de abastecimento e resposta em tempo útil, face à procura requerida.

A procura da eficiência através da optimização da relação qualidade/preço/serviço/prazo no processo logístico, associada à selecção e aquisição dos diferentes produtos que integram o catálogo centralizado, necessita de três componentes: liderança económica e técnica; envolvimento dos diversos agentes no processo logístico; redução da gama de produtos e concentração de fornecedores.

A procura de eficiência neste campo só será possível se o processo tiver liderança económica e técnica efectiva. A liderança económica exercer-se-á através da articulação de programas de actuação nas suas diversas facetas: acordos entre os vários intervenientes no processo de decisão, negociação com fornecedores, substituição e introdução de produtos, programação de cursos e seminários, gestão de necessidades e políticas de preços. Todavia esta liderança não é suficiente em si mesma.

As características das organizações de saúde e a estrutura dos produtos que integram o seu catálogo tornam necessária a existência de um parecer técnico sobre a selecção de produtos, sobre a qualidade e rendimento da sua utilização, bem como os critérios que permitam efectuar o consumo eficiente dos mesmos. Este parecer só poderá ser concretizado pelos responsáveis clínicos, sejam estes médicos ou enfermeiros, em função da natureza dos produtos aplicados e das características da organização. A unidade de aprovisionamento deverá reforçar e complementar este parecer técnico, apoiando logisticamente o desenrolar da actividade assistencial, formulando perguntas e articulando o processo logístico. Mas o parecer técnico projecta-se em actuações que fomentam a participação dos diferentes profissionais que utilizam produtos no desenrolar da sua actividade de assistência. Deste modo, a constituição de Comissões Técnicas permite integrar a experiência dos diferentes profissionais para determinar a qualidade requerida e a sua normalização.

Com a terceira linha estratégica, adequar a estrutura organizacional e a legislação aos novos modelos de gestão, pretende-se, por um lado, que o modelo a implementar, aberto e flexível, seja capaz de gerar concorrência na oferta e obter desta forma ofertas mais competitivas em favor dos consumidores; por outro, que o enquadramento legal e a estrutura organizacional da Central se constituam num instrumento aliado, orientado para a rapidez de resposta exigida ao processo de aprovisionamento. 


\subsection{Critérios gerais}

Na concepção do modelo de gestão para a Central de Compras são preocupações constantes a qualidade e adequabilidade dos produtos, a rapidez de resposta no processo de aprovisionamentos, a participação e cooperação dos interessados e por consequência a inovação. Somos, assim, conduzidos a definir como princípios orientadores e centrais da política de aprovisionamentos os seguintes critérios gerais:

1. satisfação das necessidades dos clientes;

2. adequada orientação em função das reais capacidades das Instituições;

3. flexibilidade como um princípio, descentralização como uma solução organizativa e participação como a forma de actuação;

4. informação suficiente e acessível;

5. mecanismos estimuladores da qualidade.

O primeiro critério, satisfazer as necessidades dos clientes, deve constituir um dos principais desafios que se colocam aos gestores das Instituições de saúde e a persecução de tal objectivo conduzirá, directamente, à procura da qualidade, entendida como satisfação dos clientes. Nesta perspectiva, o cliente (consumidor) deve ser entendido tanto na dimensão individual (enquanto paciente) como na dimensão colectiva (enquanto toda a clientela que recorre ao serviço de saúde). Note-se que, habitualmente, o(s) paciente(s) assume(m) uma posição passiva e marginal em todo o processo de utilização dos respectivos serviços, não intervindo directamente nas condições gerais de estada por forma a proporcionar melhor qualidade de vida na doença.

Uma melhor gestão dos recursos disponíveis pode contribuir, em alguns segmentos, para o incremento da eficiência, gerando, assim, poupanças a aplicar em outras valências, o que permite alterar o status actual. O aprovisionamento dos processos em que se encontra presente o paciente, ou quando este pode perceber uma perca de qualidade que afecte a sua satisfação deve ser gerido com uma atenção cuidada. Também os clientes internos devem ser consultados para determinadas decisões de compras, uma vez que a satisfação dos clientes (pacientes) passa também pela satisfação destes.

Quanto ao segundo, adequada orientação em função das reais capacidades das Instituições, se considerarmos que, em muitos casos, é possível obter economias de escala ou vantagens quando se aumenta o volume das compras, duas questões se colocam: (1) pode ou deve subcontratar-se a gestão dos aprovisionamentos? (2) essa subcontratação deve abranger todos os aprovisionamentos?

Estamos a falar de compras cuja qualidade condicionará, em certa medida, a própria qualidade dos hospitais e centros de saúde. Assim sendo, a 
solução que nos parece mais viável leva à Associação de Compradores ${ }^{2}$, a fim de se conseguir uma escala ou volume de compras que fortaleça o poder negocial junto dos fornecedores. Contudo, e mesmo aqui, dois problemas se levantam: (a) se a pressão for excessiva, os fornecedores podem procurar mecanismos de defesa, como a redução da qualidade, por forma a compensar a redução dos preços. No entanto, este efeito poderá ser revertido, tendo em conta a redução esperada nos custos dos fornecedores, provocada pela concentração do volume de compras; (b) num mercado competitivo, muitas vezes, torna-se necessário às organizações optarem por estratégias de diferenciação. Se bem que grande parte dos aprovisionamentos (como as compressas, agulhas, etc.) são bastante indiferenciados, outros há, como a alta tecnologia, cuja diferenciação constitui um elemento relevante. Quanto aos primeiros, a centralização das compras dará resultados positivos sempre que os associados participem no controlo e no desenvolvimento da central de compras. Nos aspectos em que se procure a diferenciação torna-se necessário desenvolver uma gestão autónoma das compras.

Em relação ao terceiro, a flexibilidade como um princípio, a descentralização como uma solução organizativa e a participação como a forma de actuação, e no mundo actual, em que as mudanças se processam a ritmos acelerados, torna-se necessário dispor da flexibilidade suficiente para que as organizações se possam adaptar com rapidez às mudanças que ocorrem na sua envolvente. A gestão das compras complicase nos casos em que é necessário uma resposta mais ágil e rápida. $\mathrm{O}$ processo contratual, definido através do Decreto-Lei 197/99 dos contratos das Administrações Públicas, estabelece importantes limitações, fundamentalmente em tudo o que se refere ao peso burocrático e à falta de rapidez na resposta necessária ao aprovisionamento. A Central de Compras deve ser capaz de dar resposta às constantes mudanças que ocorrem, tanto em cada um dos serviços como em cada um dos hospitais e sub-regiões de saúde. Dotar de flexibilidade e de rapidez de resposta esta Central constituiria, sem dúvida, o principal desafio, ao mesmo tempo que os hospitais procederiam a uma progressiva descentralização.

Neste "mundo" descentralizado, a informação suficiente e acessível torna-se de importância capital à tomada de decisões, o que requer novos desenvolvimentos informáticos para dar resposta às novas necessidades. Para este tipo de trabalho é necessário uma tecnologia de informação moderna que ofereça informação fidedigna e em tempo real e que favoreça as comunicações no sentido de facilitar a gestão dos aprovisionamentos e das compras. É fundamental, para o êxito do projecto, que todas as Unidades de Consumo, a Central de Compras e os potenciais fornecedores estejam interligados por um sistema de informação e que este permita a 
utilização de uma linguagem comum. Isto é, o suporte informático deverá permitir: o expediente administrativo, a gestão de "stocks", estabelecer as obrigações de pagamento e controlo de facturas, facilitar a gestão do material inventariado, etc.

Quanto ao último, mecanismos estimuladores da qualidade, deverão ser entendidos numa tripla perspectiva: técnica, satisfação dos clientes e controlo dos custos.

\subsection{Aspectos estratégicos a considerar na Política de Aprovisiona-mento}

Segundo Porter (1988), o objectivo competitivo de cada empresa é encontrar um posicionamento no seu sector, por forma a poder defender-se das forças competitivas adversas ou, inclusivamente, colocá-las a seu favor. Tendo consciência das diferenças existentes entre o sector público e privado, o conceito de competitividade pode ser entendido como um proxy do conceito de eficiência mais ajustado às instituições de serviço público. Assim, dos cinco aspectos (Rivalidade no Sector, Produtos Substitutos, Barreiras à Entrada, Poder Negocial dos Clientes/Compradores, Poder Negocial dos Fornecedores) que influenciam de forma directa o jogo de forças de um mercado competitivo, referenciamos apenas dois por se encontrarem mais intimamente relacionados com a análise das políticas de compra dos Hospitais e Sub-regiões de Saúde e pela sua importância para a cadeia de valor e suas modificações: o poder negocial dos compradores e o poder negocial dos fornecedores.

Quanto ao primeiro (poder negocial dos compradores), um aspecto essencial a reter é o facto de os compradores tenderem a competir, especialmente quando sujeitos a restrições económicas. Assim, forçam a baixa dos preços ou o aumento da qualidade dos serviços, obrigando os fornecedores a competir entre si em benefício dos seus clientes. Este benefício será tanto maior:

1. quanto mais se compra, não apenas tendo como referência o número de unidades mas, sobretudo, atendendo ao volume da facturação. Se um fornecedor vende a um cliente $50 \%$ da sua produção, a sua sobrevivência depende muito do comportamento e atitude desse cliente;

2. se o comprador gasta muito dinheiro num produto ou serviço tende a exercer uma maior pressão sobre os custos ou a procurar uma melhoria na qualidade do serviço;

3. se os produtos ou serviços não são demasiado diferenciados, o comprador não terá grande dificuldade em mudar de fornecedor; 
4. quanto maior a ameaça de integração a montante, é possível que uma Unidade de Consumo decida deixar de subcontratar um serviço quando os seus custos ou sua qualidade possam melhorar em relação à situação de referência. Se esta opção constitui uma possibilidade real, então será uma forma importante de exercer pressão (como exemplo, refira-se a possibilidade de utilização de genéricos).

Em relação ao segundo aspecto (poder negocial dos fornecedores), os fornecedores podem exercer poder negocial sobre os compradores com a ameaça de aumento de preços ou redução da qualidade dos seus produtos ou serviços. Convém, no entanto, distinguir os fornecedores de serviços dos de produtos. Os fornecedores de serviços pouco diferenciados, como por exemplo os contratos de limpeza, são de fácil substituição. Outros, pelo contrário, como os fornecedores de informática, proprietários do sistema fechado de que se depende, têm um enorme poder, não sendo fácil a sua substituição. Nestas condições, é possível aproveitar estas vantagens de muitas maneiras, principalmente aumentando os preços ou diminuindo a qualidade. Os fornecedores de produtos estão também em posições muito diferentes. Nos aprovisionamentos pouco diferenciados (ex: compressas, seringas, etc.), o poder de negociação está no comprador. À medida que se incrementa a diferenciação do produto, aumenta o poder relativo do fornecedor, sempre que este consiga induzir a procura do seu produto, podendo então impor preços mais elevados. O caso extremo é quando os clientes se encontram "acorrentados" pelos fornecedores, como é o exemplo dos laboratórios de análises clínicas que aceitam uma nova máquina em troca da utilização dos reagentes desse fornecedor.

Vejamos agora que situações podem contribuir para aumentar o poder dos fornecedores no sector da saúde:

1. os fornecedores estão mais concentrados que os compradores;

2. o comprador é de pequena dimensão ou compra em pequenas quantidades;

3. fraca concorrência nos produtos;

4. o produto é muito importante para o comprador, dependendo do seu grau de diferenciação;

5. o fornecedor representa uma ameaça real de integração a jusante.

Estas considerações devem ser tidas em conta ao longo do processo de tomada de decisões sobre a gestão das compras.

\subsection{Estrutura organizacional da Central de Compras}

A concepção/desenho da organização da Central de Compras deve assentar numa estrutura leve e flexível, sem armazenamento nem 
distribuição, capaz de dar resposta às permanentes mutações da envolvente. Por outro lado, deve ser enquadrada num sistema aberto que permita a participação dos vários actores envolvidos no processo. Conjuntamente, o seu suporte informático de base deve permitir a operacionalidade do sistema.

\subsubsection{Estrutura das relações externas}

Tendo por base tudo o que foi referido anteriormente, a Central de Compras funcionará como o elemento de ligação, ao nível da estrutura das relações externas no tocante ao processo negocial, entre as Unidades de Consumo e os respectivos fornecedores (fig. 2). Contudo, dependendo dos possíveis cenários de funcionamento da Central, este elo de ligação poderá ser tanto mais forte quanto maior for o nível de centralização (ex: centralização da tramitação dos pedidos e dos processos de pagamento).

Figura 2

\section{ESTRUTURA DAS RELAÇÕES EXTERNAS}

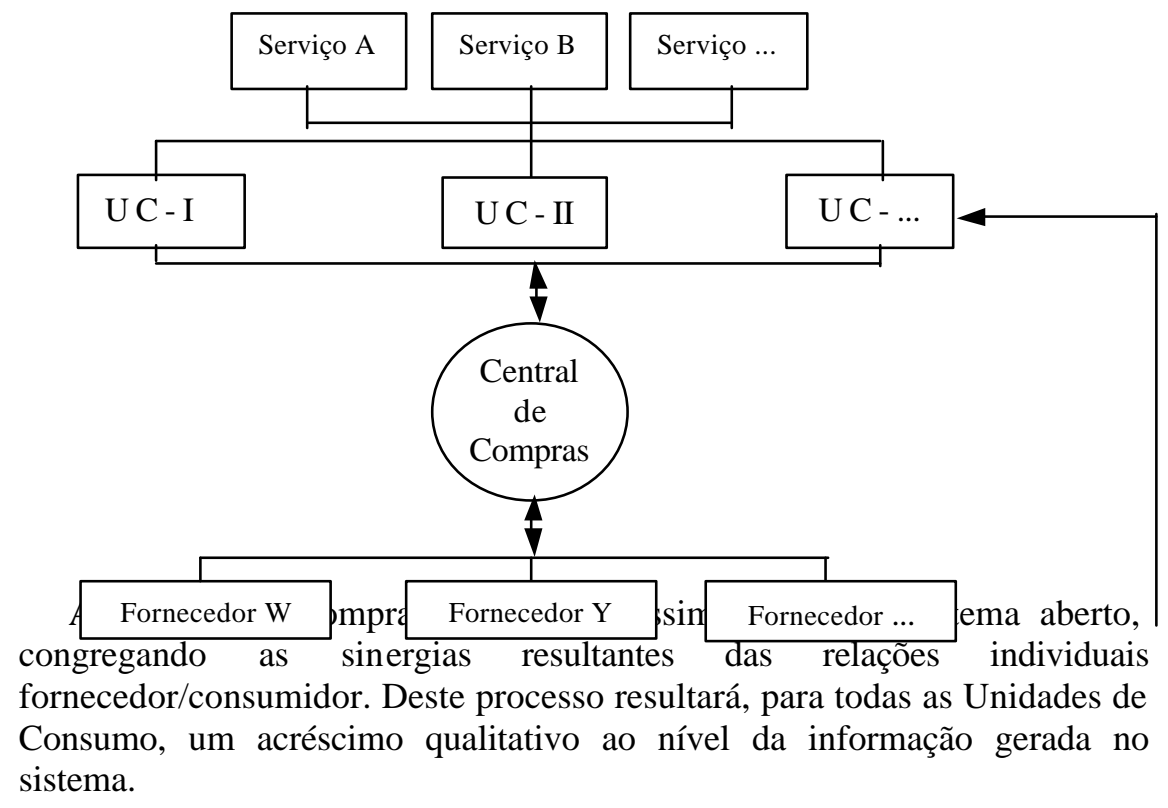

\subsubsection{Estrutura das relações internas}


Esta estrutura assenta num modelo matricial como resultado da interacção entre uma estrutura divisional por famílias de produtos (gestores/ negociadores) e uma estrutura funcional (serviços administrativos) (fig. 3).

Figura 3

ESTRUTURA DAS RELAÇÕES INTERNAS

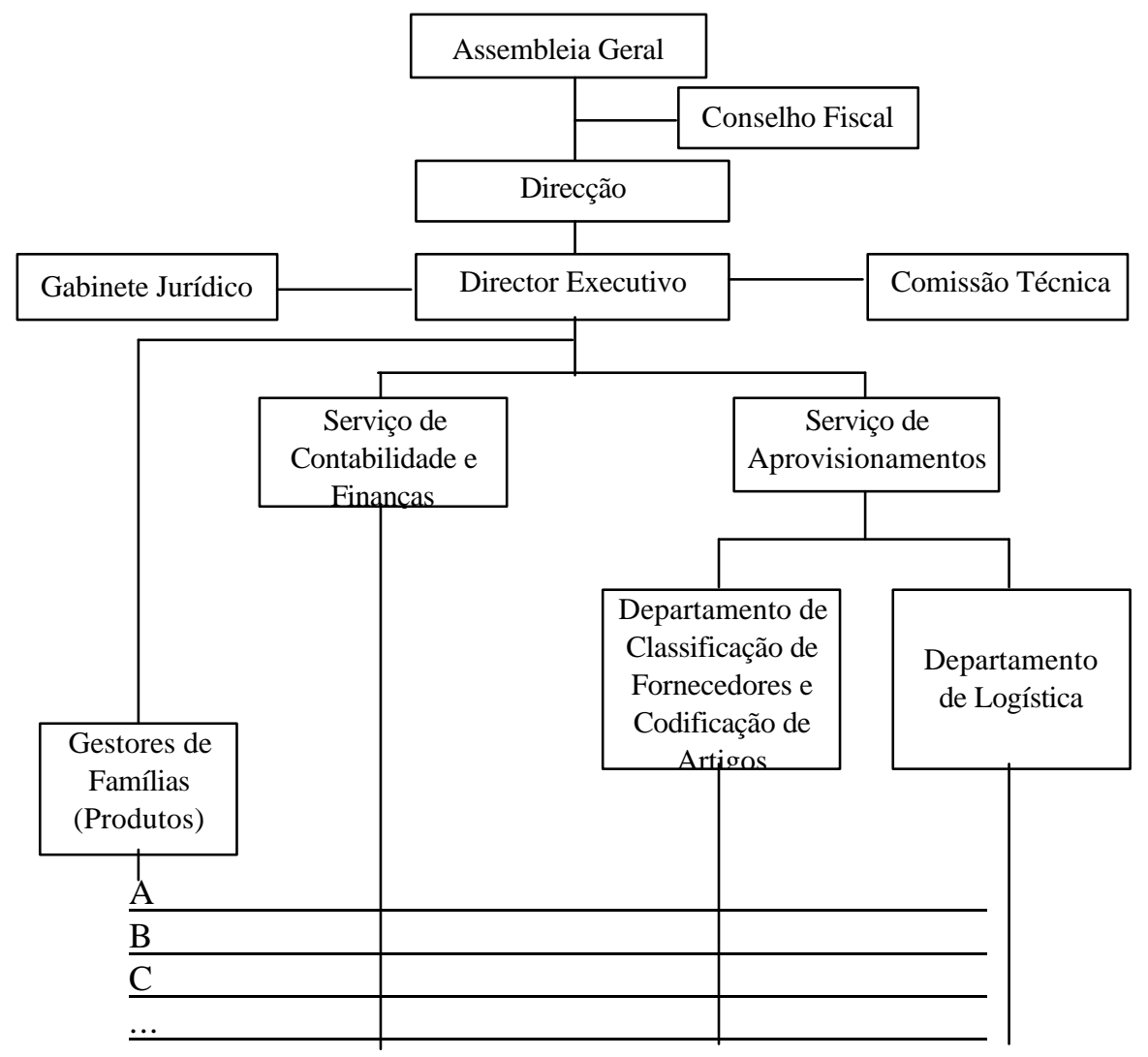

Para além dos órgãos de gestão a definir segundo a forma jurídica que a Central vier a adoptar, esta deverá conter na sua estrutura órgãos de "staff" (Comissão Técnica e Gabinete de Apoio Jurídico), órgãos executivos (Director Executivo e Gestores Negociadores) e serviços de apoio administrativo (Serviço de Contabilidade e Finanças e Serviço de Aprovisionamentos).

A Direcção da Central de Compras, independentemente da sua figura jurídica, deverá conter na sua constituição representantes das diversas Unidades de Consumo e da ARS-Norte. Estes funcionarão como um órgão executivo colegial cabendo-lhe, entre outras, as seguintes funções: dar 
execução às deliberações da Assembleia Geral; criar as Comissões Técnicas e outras Comissões Especializadas; organizar e superintender os serviços da Central; cumprir e fazer cumprir os acordos elaborados entre a Central e terceiras pessoas ou entidades; diligenciar pela obtenção de empréstimos; propor à Assembleia Geral a criação de serviços aos sócios, de acordo com regulamento a elaborar; etc.

A Comissão Técnica, oriunda dos corpos técnicos das respectivas Unidades de Consumo, será o órgão colegial para a tomada de decisões no que diz respeito aos produtos, no sentido de garantir a qualidade e adequabilidade dos mesmos.

Ao Gabinete de Apoio Jurídico, a funcionar em regime de avença, caberá a responsabilidade formal e legal sobre os aspectos de caracter jurídico.

O Director Executivo, nomeado pela Direcção, terá como função principal a coordenação de todas as actividades da Central.

Às equipas de Gestores/Negociadores de famílias/produtos compete optimizar, através do processo de negociação, a relação qualidade/preço/quantidade/condições de fornecimento e em simultâneo gerir as respectivas famílias/produtos em todo o seu processo de aprovisionamento facilitando assim informação, em tempo real, quer sobre o mercado da oferta quer sobre o grau de satisfação dos respectivos utilizadores/consumidores.

O Serviço de Aprovisionamentos proporcionará o suporte administrativo através de duas unidades especiais: Departamento de Classificação de Fornecedores e Codificação de Artigos e Departamento de Logística.

Ao Departamento de Classificação de Fornecedores e de Codificação de Artigos compete propor as regras de normalização e codificação dos produtos a centralizar para a negociação (família, grupo, subgrupo, etc.), identificação e classificação dos respectivos fornecedores e o controlo do sistema.

Ao Departamento de Logística compete receber e canalizar os pedidos das várias Unidades de Consumo, com referência às famílias de produtos cujas aquisições se tenha decidido centralizar. A formulação dos pedidos aos adjudicatários, em relação a estes produtos, é da exclusiva responsabilidade do Departamento de Logística da Central, especificando em cada pedido os produtos a entregar pelo fornecedor a cada Unidade de Consumo, pelo que se deverão implantar e desenvolver sistemas de informação automatizados adequados. Por outro lado, este Departamento deverá propor as directrizes que conduzam à optimização da gestão económica de "stocks" das várias Unidades de Consumo e implementar um sistema de controlo da qualidade definida para os produtos.

Uma vez mais, pensada desta forma e tendo por base o referido suporte informático, a Central de Compras funcionará como o elemento facilitador 188 
da negociação e aquisição entre as Unidades de Consumo e os respectivos fornecedores.

\section{PRESSUPOSTOS DE SUCESSO}

A implementação destes princípios só será possível com o cumprimento e aceitação (por parte de todas as Unidades de Consumo ou pelo menos das mais relevantes) dos seguintes pressupostos de partida, que darão forma a um modelo evolutivo:

- motivar as Unidades de Consumo para o projecto e assegurar o seu comprometimento ao longo do mesmo;

- mobilizar, envolver e formar os diferentes grupos de interesse;

- os benefícios devem ser repartidos por todos os grupos de interesse, assegurando a sua motivação;

- elaboração de planos anuais de consumo, por parte de todas as Unidades;

- introduzir gradual e selectivamente os produtos e serviços no processo de centralização;

- concertação da política de aprovisionamento;

- aumento da frequência de entregas por parte dos fornecedores;

- enfoque no "Just in Time";

- simplificação, automatização e planificação dos processos de aprovisionamento;

- não definir objectivos apenas numa óptica financeira;

- implementação de um sistema de informação que permita integrar as actividades de: requisição, entrega, gestão dos armazéns, expedientes e pagamentos, num espaço de tempo "real", de todas as Unidades de Consumo com a Central de Compras e em simultâneo com os respectivos fornecedores (um dos sistemas que pode ser utilizado neste procedimento é o sistema EDI-Intercâmbio Electrónico de Dados ou qualquer outro alternativo) (fig. 4);

Figura 4

MECANISMO DE COMUNICAÇÃO

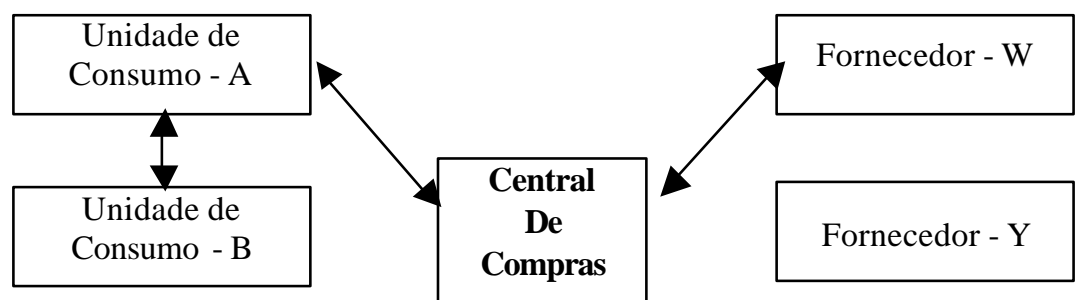



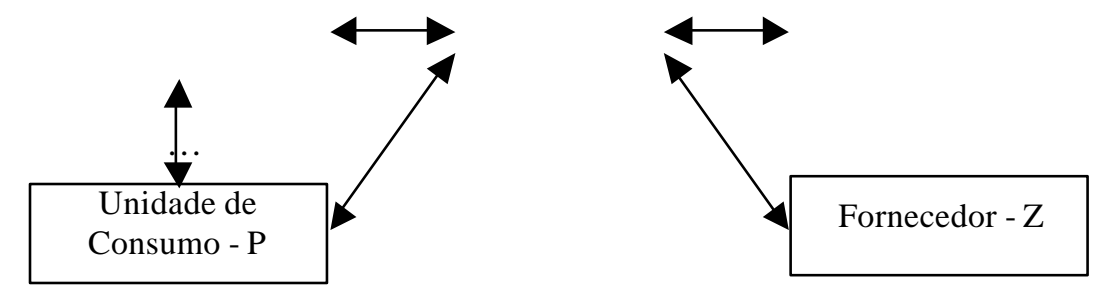

- optimização das variáveis chave; custo total, ciclo temporal, qualidade e valor para o paciente, através da integração das suas diferentes componentes; pessoas, processos, organização e sistemas (fig.5).

Figura 5

INTERLIGAÇÃO DAS VÁRIAS COMPONENTES

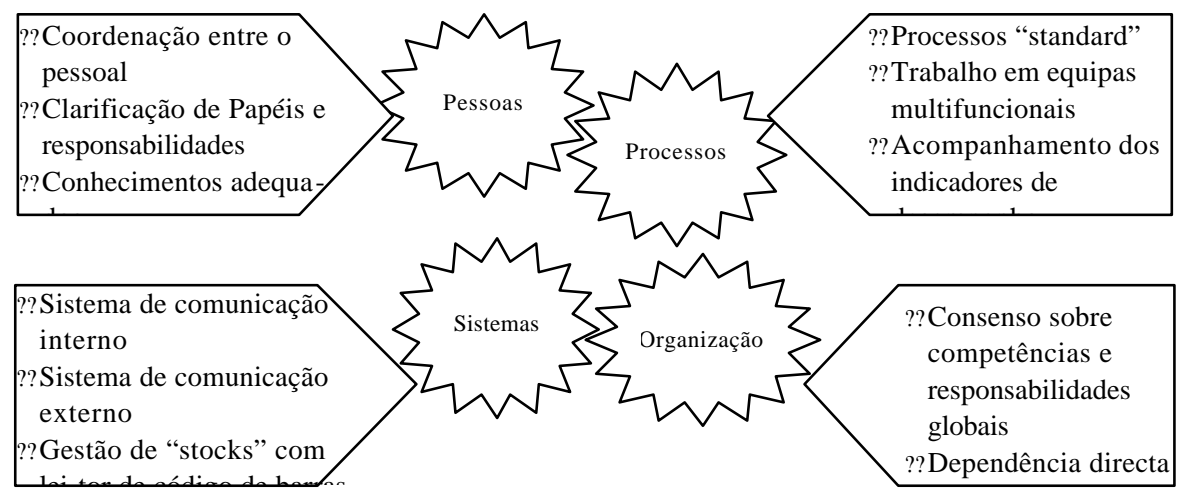

\section{RESULTADOS ESPERADOS}

Da centralização das compras e da concertação dos aprovisionamentos resultarão benefícios importantes: quantificáveis e não quantificáveis, financeiros e não financeiros (fig. 6):

\section{Figura 6}

BENEFÍCIOS QUANTIFICÁVEIS E NÃO QUANTIFICÁVEIS, FINANCEIROS E NÃO FINANCEIROS
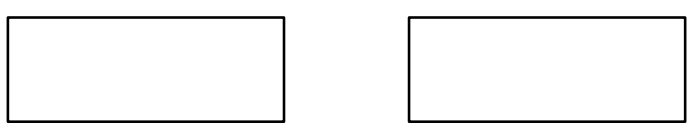
Financeiros
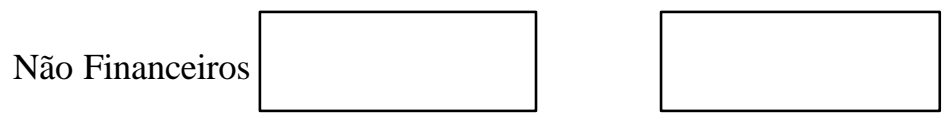

\section{- Benefícios financeiros quantificáveis e não quantificáveis:}

Os benefícios financeiros estão normalmente associados a reduções de custos e reduções no capital circulante.

- Reduções de Custos:

- reduzir o custo unitário através da agregação de volumes e/ou consolidação de fornecedores;

- reduzir gastos através da estandardização de produtos e utilizações;

- reduzir o custo total.

- Reduções no Capital Circulante:

- reduzir os gastos de manutenção de "stocks" (financeiros e administrativos);

- vender (evitar comprar) "stocks" excedentes;

- impacto negativo na existência de "stocks" fora do prazo de validade.

\section{- Benefícios não financeiros quantificáveis e não quantificáveis:}

Muitas vezes os benefícios, não financeiros, assumem maior relevância pelo valor acrescentado que transportam para a organização:

?? melhorias nos níveis de serviços;

?? maior motivação;

?? melhoria da comunicação entre os diversos grupos de interesse;

?? aumento da eficácia nas transações;

?? redução do tempo de espera dos produtos;

?? maximização da utilização da capacidade;

?? melhor informação sobre as ofertas de mercado;

?? redução no tempo gasto com a emissão de pedidos;

?? segurança dos aprovisionamentos;

?? maior e melhor controlo qualitativo e quantitativo dos produtos;

?? percepção do valor acrescentado nas compras;

?? inovação. 


\section{CONCLUSÕES}

Tentando sintetizar tudo o que foi dito anteriormente, podemos dizer que qualquer processo centralizado de aquisições deverá ter em conta o seguinte:

?? O sistema competitivo em que as organizações, quer privadas quer públicas, desenvolvem a sua actividade centra-se em mecanismos de procura da melhor qualidade ao menor preço;

?? A política de compras não é uma política isolada, mas sim integrada na área financeira que, por sua vez, tem de ser harmónica com as restantes. Deve ser desenvolvida através de um Plano Operacional ou Sistema de Compras com o correspondente manual de procedimentos, que permita a sua avaliação;

?? O envolvimento de todos os profissionais de saúde no sistema de aprovisionamentos terá de ser uma constante já que, ao fim e ao cabo, são estes os decisores últimos sobre os consumos, tendo em conta os critérios de satisfação dos clientes (pacientes) no seu desempenho. A proposta feita pelos autores à ARS-Norte dá importância central à criação e funcionamento de um sistema de gestão integrada dos aprovisionamentos, que representa não só o pré-requisito básico para alcançar os objectivos da Central, mas também é fruto do seu posicionamento em elos na cadeia de valor actualmente ocupados por outros actores.

?? Segundo os princípios da cadeia de valor torna-se necessário incrementar o associativismo e a cooperação. Assim, o modelo de outsourcing na gestão das compras sob controlo da Central de Compras é, quanto a nós, uma boa solução para a política de aprovisionamentos da maioria dos produtos;

?? Dispor de tecnologia de informação (afim de realizar uma eficaz gestão de "stocks", gestão de rede de fornecedores, comparação de preços e integração das unidades de consumo), necessária para conseguir um bom desempenho, convertendo-se aquela na chave imprescindível para o seu desenvolvimento.

Assim, e ainda em jeito de conclusões, podem salientar-se como mais relevantes os seguintes pontos:

1) a Central de Compras visa assegurar, à luz de uma nova racionalidade, a centralização da aquisição de bens e serviços para as Unidades de Consumo da zona de intervenção da ARS-Norte, procurando alcançar uma maior eficiência e eficácia do funcionamento global do sistema de saúde e consequentemente uma redução dos respectivos custos. Tratando-se de uma experiência inovadora, ao nível nacional, no momento em que se questionam 
profundamente as funções e o papel das instituições de saúde e numa área em que a clientela final (paciente) é o homem, o desenvolvimento e execução do projecto deverão ser comparados a aspectos de elevada cultura profissional e profunda sensibilidade humana.

2) A centralização deve processar-se de forma gradual e selectiva. Primeiro, porque depender-se-á do processo cuidadoso de renegociação dos papéis e posições respectivas dos diferentes actores na cadeia de valor; segundo, porque o processo de centralização deve começar com os produtos que maior frequência de utilização têm;

3) A entidade enquadradora da Central de Compras deve ser autónoma e resultar da cooperação/associação das Unidades de Consumo.

Terminamos com as palavras de Ronald Henkoff: "Face aos desafios das economias modernas, os serviços audazes, rápidos, imaginativos e personalizados são o imperativo estratégico fundamental".

\section{NOTAS}

\footnotetext{
${ }^{1}$ Este conceito tem o seu desenvolvimento no estudo entregue à ARS-Norte.

${ }^{2}$ Estas Associações de Compradores assumem, em modelos mais elaborados, ao nível dos diversos sectores, a figura de uma Central de Compras.
}

\section{BIBLIOGRAFIA}

ASTORQUI, F.; BENGOECHEA, J. (1997), Desarrollos que permitem mejorar la gestión de stocks. Conferencias Expansión-Tir.

ASTORQUI, F.; BENGOECHEA, J. (1999), "Strategic analysis of the hospital sector and new healthcare reforms", The Economist Conferences. The future of Europe's hospitals.

BENGOECHEA, J.; ECHÁNIZ, I. (1997), "Aspectos práticos de la Planificación Estratégica en el sector sanitario".

CAMACHO, A.; CRUJEIRA, C.; LUCENA, J.; PINHO, I. (1982), GESTÃO PÚBLICA uma abordagem integrada, Livros Técnicos e Científicos, Lda.

CILD, J. (1989), Organización. Guia para problemas y prática. Ca. Ed. Continental. 
HOLMES, M. \& SHAND, D. (1995), "Management Reform: Some Practitioner Perspectives on the Past Tem Years", Governance, v. 18, n 4.

KENKOFF, R. (1994), "Services are the busines for everybody". Fortune. June, 27.

MINZBERG, H. (1982), "La necessidad de coherencia en el discño de la organización", Harvard-Deusto B. R. 3 - trim.

MINTZBERG, H. (1984), La estructuración de las organizaciones, Ed. Ariel.

MINTZBERG, H. (1994), The Rise and Fall of Strategic Planning, U.K., Prentice Hall.

NAVARRO CASTILLO, F. (1995), La dirección estratégica de costes. Fundamentos, Instituto de Empresa.

PORTER, M. E. (1990), The Competitive Advantages of Nations, London, The Macmillan Press Ltd..

PORTER, M. E. (1988), Estratégia Competitiva - Técnicas para Análise de Indústrias e da Concorrência, Campus, Rio de Janeiro.

Recoletos Conferencias \& Formacion (1999), 'Compras Hospitalarias' 99, Documentaciones facilitadas por los ponentes, Madrid.

ROCHA (1996), Comunicação Pessoal, Policopiado. 